\title{
Sobre el criterio de legitimidad de las leyes
}

\section{Carmen Trueba Atienza}

$\mathbf{L}$

o que me propongo aquí es discutir algunos aspectos medulares de la interpretación y evaluación de Livio Rossetti de la legislación platónica tocante a la impiedad, en el artículo "El ateísmo como delito extremo en las Leyes de Platón".'

Rossetti centra su análisis de la cuestión en el libro décimo de las Leyes, en donde el filósofo griego se ocupa de la impiedad. El examen cuidadoso de la codificación platónica sobre la impiedad y sus principios, en el contexto de la reforma política que Platón propone en su obra con miras a reforzar "la maquinaria pública", lleva al autor a plantear que "lo que está detrás del conjunto de prescripciones particulares [es] una verdadera estrategia de promoción de la interiorización de las reglas y los valores, y, por tanto, de una conducta correcta por parte de la mayoria de los habitantes" (p. 78).

Livio Rossetti propone una interpretación contextual de la obra codificadora platónica en comparación con otros antiguos códigos; destaca el carácter de las medidas y los castigos introducidos por Platón, algunos de ellos totalmente inéditos en el mundo antiguo, como la condena a una prisión temporal en "centros de readaptación social" (sophonisterion), o la prisión prolongada y vitalicia (timoría). A su juicio, "Platón muestra una gran moderación para su época", pues "la eliminación física es concebida como último recurso para asegurar la supervivencia [...] de la vida en sociedad" (p. 82), y la legislación sobre la impiedad "se abstiene de considerar toda hipótesis de sanción sádica o de tortura (si no es la tortura ritual de los esclavos...) u otras formas de castigo que puedan ser consideradas peores que la muerte" (p. 83, el subrayado es mío).

${ }^{1}$ Livio Rossetti, "El ateísmo como delito extremo en las Leyes de Platón", en Re. vista del Colegio de Filosofía. Theoria, núm. 6. México, Facultad de Filosofia y Letras, julio, 1998, pp. 75.86. (Los números entre paréntesis remiten a las páginas de este artículo.) 
Para Rossetti, "el principio inspirador es siempre la búsqueda de un criterio de organización de la vida pública y privada que sea capaz de impedir el relajamiento de las costumbres" (p. 77). El interés platónico, en efecto, está puesto sobre todo en propiciar la cohesión social y la estabilidad del orden social: la salud de la polis y su conservación, entendidas en un sentido muy particular, de ahí que me parezca relevante discutir el significado de la "interiorización de las normas" en las Leyes.

Los términos en que Platón concibe la "interiorización" de las normas, en las Leyes, resultan significativamente distintos de la paideia promovida en la República, considerando que las disposiciones legales apuntan en buena medida a una "política de honores" tendente a configurar y reforzar un sistema de aspiraciones y metas colectivas, a través de un sistema de premios y castigos.

Un ejemplo de lo anterior son las disposiciones relativas al deber impuesto a todo testigo, independientemente de su condición social, de intervenir activamente y prestar ayuda a cualquier persona libre agredida. ${ }^{2} \mathrm{Si}$ atendemos al conjunto de medidas estipuladas por Platón, es posible advertir que se dirigen a propiciar un pego a las normas cifrado más en un cálculo estratégico que en la convicción interna del deber fundado en la verdad y en un principio incontrovertible de justicia, a diferencia de lo que plantea en la República, en donde se sostiene expresamente que el fundamento moral de la legalidad y de la vida política no puede ser la fuerza coactiva de la norma ni el temor al castigo, o la mera expectativa de recibir una recompensa.

En comparación con el papel de primerísima importancia que Platón le concede directamente a la educación en la República, y a pesar de que no deja de considerar el papel educador y formativo de las leyes, ${ }^{3}$ el filósofo parece juzgar que la función educadora de la ley es bastante menos efectiva que su función punitiva o represiva, sobre todo en relación con algunas conductas violentas que considera particularmente graves, en cuyo caso propone una terapéutica legal basada en la función disuasiva y en la naturaleza coercitiva de las leyes en general. ${ }^{4}$

Para Rossetti, las Leyes representan un progreso en el pensamiento politico de Platón, en comparación con la República (p. 79). Esta opinión es sumamente debatible. En primer lugar, porque el juicio hace caso omiso de algunas diferencias entre ambas obras, en cuanto a su naturaleza e intención filosófica, a las cuales haré referencia brevemente. Pero antes quisiera aclarar mi posición al respecto, pues a diferencia de Livio Rossetti, concuer-

\footnotetext{
${ }^{2}$ Platón, Leyes, $\mathrm{xx}, 881$.

${ }^{3}$ Ibid., $\mathrm{x}, 880 \mathrm{~d}$.

${ }^{4}$ Ibid., x, $8811 \mathrm{a}-882$.
} 
do con quienes, como Christopher Rowe, ven la República platónica como una obra de reflexión crítica y una especie de ejercicio o experimento de la imaginación y el pensamiento, más que un proyecto utópico concreto. ${ }^{5}$

Un indicio de lo anterior es que Platón se muestra, en la República, muy poco interesado por los problemas relativos a la implantación del orden ideal, ${ }^{6}$ de ahí que resulte cuestionable que su posición haya sido, como Rossetti piensa, la de "contentarse con esperar que un buen filósofo o un buen príncipe tomase el poder y supiese cómo reorganizar y dirigir el Estado" (p. 78).

La preocupación platónica es otra en las Leyes; pareciera que el propósito ya no es indagar cuál sería el orden político ideal o perfecto, sino descubrir las leyes capaces de garantizar un funcionamiento social jerárquicamente ordenado y estable. Es en este espíritu que el filósofo concibe algunas medidas de control que serían ejercidas por la comunidad en su conjunto -como la vigilancia y reprobación de cualquier desviación de la norma, por parte de cualquier miembro de la polis (p. 79)-, las cuales no vienen a ser más que variantes un poco más sofisticadas de los sistemas de censura social tradicionales.

A mi juicio, uno de los problemas más graves es que Platón sólo atiende, en las Leyes, al efecto que considera deseable y positivo de ese tipo de medidas de control social, concretamente la obediencia de la ley por parte de los miembros de la comunidad, pero no toma en cuenta otros efectos indeseables. Por su parte, Rossetti tampoco toma en cuenta que las medidas de control propuestas por Platón, imprimirían a las relaciones entre los ciudadanos y a la vida social en su conjunto un sesgo policiaco, extremadamente peligroso y restrictivo para el individuo; precisamente el mismo que llevara a Anito y Melito a levantar la acusación formal contra Sócrates de no respetar los dioses de la ciudad y venerar una deidad particular.

Es necesario preguntarse, por lo tanto, equé clase de "progreso esencial" entrañaría, como pretende Rossetti, el hecho de que la salvaguarda del orden político, en lugar de quedar en manos de un rey filósofo o un príncipe bueno, dependa de "una estructuración coordenada y clarividente de casi

' Christopher Rowe excluye que la República contenga un conjunto de propuestas políticas y constituya un auténtico proyecto arquitectónico, y la concibe primariamente como una obra de reflexión crítica. (Cf. "Matar a Sócrates: los pensa. mientos tardios de Platón acerca de la democracia", en Revista del Colegio de Filosofía. Theoría, núm. 6. México, Facultad de Filosofia y Letras, julio, 1998, p. 71.)

' Personalmente, no creo que Platón haya pretendido dejar todo en manos de un monarca filósofo; de hecho, en la Repüblica concibe todo un sistema social capaz de generar un orden politico estable, a partir de un criterio universal y necesario de justicia. Al respecto, véase mi artículo "Sócrates y la revolución sofista", en Estudios, núm. 36, 1995. 
todo elemento de la vida social, de manera que el propio ciudadano, el extranjero, la mujer, puedan concurrir al respeto efectivo (no sólo formal) de las leyes"? (p. 79, el subrayado es mio).

Me parece que habría que cuestionar la naturaleza de tal "clarividencia política", pues más allá de que el derecho de ejercer la censura se expanda y se haga extensivo a los huéspedes, extranjeros residentes y las mujeres, en última instancia, lo que interesa desde un punto de vista filosófico y político no es el problema práctico de cómo garantizar el cumplimiento de las leyes o su acatamiento por parte de los ciudadanos, sino otra cuestión más de fondo y extremadamente polémica, a saber, el criterio mismo de legitimidad de las leyes y del orden político y social al que sirven de base, al igual que el fundamento político de la obediencia ciudadana de las leyes. Cuestiones que, como se sabe, Platón trata en la República, cuando recurre a la fábula del anillo de Giges y critica que el fundamento del deber y la legalidad consista en el temor al castigo, pues considera que un orden social sentado sobre tales bases sería sumamente vulnerable y estaría expuesto permanentemente a las infracciones.

Livio Rossetti contrasta el juicio platónico sobre el ateísmo como delito merecedor de la pena de muerte, con la visión moderna, para la cual los delitos ideológicos no cuentan como delitos extremos, dignos de la pena máxima (p. 85). Platón asigna al ateísmo, la forma extrema de impiedad, el castigo máximo en razón de su efecto político disolvente. ${ }^{7} \mathrm{Al}$ respecto, cabe resaltar que Platón comparte básicamente la visión de sus contemporáneos acerca del efecto político del escepticismo racionalista y el naturalismo ${ }^{8}$ y asume que el núcleo de creencias religiosas compartidas constituye un fundamento imprescindible de la vida social.

Para Platón, como para la mayoría de los griegos, toda forma de escepticismo en materia religiosa constituía una posible causa de disolución del orden político. Pero es importante advertir que la posición platónica encierra una condena de la impiedad tan rigurosa o quizás más todavía que la vigente en la legislación ática, pues no sólo censura la impiedad en cuanto incitación abierta a la infracción del orden, como un factor de división social, de relajamiento de las normas y pérdida de vigor de su poder coactivo; Platón subraya incluso que la forma más peligrosa de ateísmo es aquélla que va aunada a la honestidad, ${ }^{9}$ porque la conducta virtuosa del ateo podría minar la confianza popular en el fundamento tradicional de la moralidad y la legalidad. A fin de cuentas, el autor de las Leyes presupone que una vía bas-

\footnotetext{
7 Platón, Leyes, $\mathrm{x}, 885 \mathrm{~b}$.

${ }^{8}$ Ibid., $\mathrm{X}, 891$.

${ }^{9}$ Ibid., 908b-d.
} 
tante segura para inducir al pueblo ignorante a actuar conforme a la ley es el temor al castigo divino y la esperanza de agradar a los dioses.

En cuanto a la ausencia de crueldad y sadismo en el código penal platónico, considero que la opinión de Rossetti resulta un tanto sesgada. La ausencia de castigos como la tortura física y otras modalidades de crueldad son, para él, un indicio del carácter moderado de la codificación platónica relativa a la impiedad. Sin embargo, siguiendo a Trevor J. Saunders, ${ }^{10}$ creo que es posible comprender la naturaleza de las penas propuestas por Platón a la impiedad a partir de otros elementos presentes en su obra, que atañen directamente a su concepción curativa o terapéutica de las leyes.

Para Platón, las leyes no sólo cumplen una función reguladora y retributiva. El legislador, como un buen médico, debe saber aplicar la medicina apropiada para cada tipo de mal; es importante que conozca las distintas especies de males; debe establecer en cada caso qué tipo de acción u omisión ha sido cometida, evaluar la falta, dictaminar su gravedad y la sanción debida. La codificación platónica utiliza una serie de criterios más o menos tradicionales, de índole religiosa y política, como el status de las partes, la infractora y la agraviada, de acuerdo con su condición (divina/humana/animal, libre/esclava, anciana/joven, ciudadana/extranjera residente/huésped), la relación social o el parentesco habido entre el agente y la víctima, el estado psicológico en que se comete el delito (ignorancia, locura, enfermedad, impulsividad, etcétera), la forma en que es cometido (de palabra o hecho, pública/privada, violenta/no violenta), su frecuencia o reincidencia.

Las diferencias entre las penas que estipula contra el delito de impiedad, y las que asigna a otros tipos de delito que considera sumamente graves, como el matricidio y la violencia contra los padres," para los cuales sí recomienda castigos corporales, pueden ser atribuidas, por tanto, no a una moderación ejemplar, sino a la convicción platónica de que la impiedad es una falta perteneciente a una especie distinta, de índole intelectual, que demanda una terapéutica especial: el ateo debe ser persuadido de su error. Platón expresamente señala que la única réplica apropiada para el ateísmo es la crítica racional y la persuasión argumentativa. ${ }^{12}$

Aunque habria que preguntarse qué tanto las penas platónicas en contra de la impiedad son de orden estrictamente simbólico, como considera Rossetti, pues no solamente la pena de muerte, sino la prisión constituye por sí misma un castigo físico y, en cierto modo, una especie de tortura.

${ }^{10}$ Trevor J. Saunders, Plato's Penal Code. Tradition, Controversy and Reform in Greek Penology. Clarendon Press, 1991.

"Platón, Leyes, Ix, 881a-882b.

${ }^{12}$ Ibid., $\mathrm{X}, 885$. 
En cuanto a la evaluación de las penas, no hay que perder de vista que lo que a nuestros ojos puede parecer como una muestra fehaciente de ausencia de crueldad, para los antiguos pudo haber resultado algo completamente distinto. Para un griego libre quizás haya resultado un castigo mucho más duro de sobrellevar el permanecer recluido y en total aislamiento, en el seno de una apartada timoría, que sufrir otro tipo de penas. Al respecto, contamos con la opinión socrática, en el Critón.

Si en materia de impiedad Platón se inclina preferentemente por castigos vergonzosos y correctivos, no hay que olvidar que en otros casos estipula penas físicas y formas de maltrato diversas, a las cuales Platón mismo considera peores incluso que la muerte, ${ }^{13}$ pero que considera el único remedio apropiado. Por ejemplo, en el caso de que un esclavo cometa por cuenta propia una agresión fisica en contra de un hombre libre, extranjero o ciudadano, los testigos quedan obligados a intervenir en defensa del hombre libre, someter al esclavo y azotarle hasta el punto que consideren conveniente, siempre y cuando no le causen perjuicios al dueño del esclavo. ${ }^{14}$

Livio Rossetti prácticamente sólo considera un caso en que Platón aprueba el uso de la violencia, a saber, la tortura de los esclavos testigos en los procesos. Su argumento es que dicha práctica constituía "una formalidad legal", e incluso podía servir de medio para proteger a los esclavos de la venganza de los amos (p. 83), puesto que los esclavos se habían visto forzados a declarar en contra de sus amos. Es preciso replicar que el que constituyese una "formalidad legal" no quita que en los hechos haya sido una prácti ca cruel y, en esa medida, reprobable; y por otra parte, es dudoso que e haber pronunciado la declaración bajo tortura, haya constituido una protección segura para el esclavo frente a la ira o una eventual venganza por parte de los amos. La única protección del esclavo ante una posible arbitrariedad de los amos pudo haber sido, en cualquier caso, el interés de los propios amos de no ver todavía más afectados sus intereses en cuanto amos.

Hay una última cuestión que me gustaría plantear: si bien es cierto que Platón introduce algunas modalidades de castigo notablemente moderadas, incluso para nuestro tiempo, en que vemos cada día multiplicarse el número de partidarios de la pena de muerte, no podemos desconocer algunos rasgos presentes en su obra, que deberían hacernos reflexionar acerca de qué tanto "la sociedad griega de esa época no conoció formas de crueldad extrema" (p. 85).

13 Ibid., $\mathrm{x}, 881 \mathrm{a}$.

${ }^{14}$ Ibid., Ix, 882b. 